\title{
Physical activity and fitness in women with metastatic breast cancer
}

Jasmine Yee ${ }^{1}$, Glen M Davis ${ }^{1}$, Jane M Beith ${ }^{2}$, Nicholas Wilcken ${ }^{3}$, David Currow ${ }^{4}$, Jon Emery ${ }^{5,6}$, Jane Phillips ${ }^{7}$, Andrew Martin ${ }^{8}$, Rina Hui ${ }^{3}$, Michelle Harrison ${ }^{2}$, Eva Segelov ${ }^{9}$, Sharon L Kilbreath ${ }^{1}$

${ }^{1}$ Faculty of Health Sciences, University of Sydney, Lidcombe, Australia

${ }^{2}$ The Chris O'Brien Lifehouse, Camperdown, Australia

${ }^{3}$ Westmead Cancer Care Centre, Westmead Hospital, University of Sydney, Australia

${ }^{4}$ Faculty of Health Sciences, Flinders University, Daw Park, Australia

${ }^{5}$ General Practice and Primary Care Academic Centre, University of Melbourne, Parkville, Australia

${ }^{6}$ General Practice, University of Western Australia, Crawley, Australia

${ }^{7}$ Cunningham Centre for Palliative Care, and The University of Notre Dame Australia, Darlinghurst, Australia

${ }^{8}$ Clinical Trials Centre, University of Sydney, Camperdown, Australia

${ }^{9}$ St Vincent's Clinical School, University of New South Wales, Darlinghurst, Australia

Corresponding Author: $\quad$ Professor Sharon Kilbreath

Faculty of Health Sciences

University of Sydney

PO Box 170

Lidcombe NSW

Australia 1825

Phone: +61293519272

Fax: +61 293519601

Email sharon.kilbreath@sydney.edu.au

Keywords: physical activity, fitness, strength, metastatic breast cancer 


\section{Abstract}

Purpose: To explore differences in physical activity and fitness between women with metastatic breast cancer compared to healthy controls, and factors associated with their physical activity levels.

Methods: Seventy-one women with metastatic breast cancer, aged (mean (SD)) 57.7 (9.5) y and 2.9 (3.1) y after onset of metastatic disease, and 71 healthy controls aged 55.0 (9.4) y participated. Of those with metastatic disease, $27 \%$ had bone-only metastases, $35 \%$ visceral-only metastases and $38 \%$ had bone and visceral metastases. Patient-reported outcomes and physical measures of muscle strength and aerobic fitness assessments were obtained. Participants wore a SenseWear® physical activity monitor over 7 days, and the average steps/day and time spent in moderate-to-vigorous intensity physical activity determined.

Results: Women with metastases were significantly i) less aerobically fit than the control group (25.3 (5.4) vs. 31.9 (6.1) ml*kg*min-1; p<0.001); ii) weaker (e.g., lower limb strength for the metastatic and control groups was 53.5 (23.7) vs. 76.0 (27.4) kg respectively; $\mathrm{p}<0.001$ ); iii) less active, with the metastatic group attaining only $56 \%$ of the mean daily step counts of the healthy women; and iv) more symptomatic, reporting higher levels of fatigue and dyspnoea $(\mathrm{p}<0.001)$.

Conclusion: Women living in the community with metastatic breast cancer possessed lower aerobic fitness, reduced muscular strength and less daily physical activity compared to healthy counterparts. They also experienced poorer functioning and higher symptom burden.

Implications for cancer survivors: Women living with metastatic breast cancer may benefit from a physical activity program to address their physical impairments. 


\section{INTRODUCTION}

In 2012, there were approximately 14,680 new breast cancers diagnosed and 2,940 breast cancerrelated deaths in Australia. For women, the risk of developing breast cancer before the age of 85 is one in eight [1]. Approximately $7 \%$ of breast cancer cases will present as metastatic disease, and a further $10 \%$ will develop metastases within 5 years of an early breast cancer diagnosis [2]. For these women, the five-year relative survival is $41 \%$ [3]. With advances in treatment significantly improving prognosis, identifying opportunities to optimise function and well-being has become increasingly important.

Although many women live long productive lives with metastatic breast cancer, there are numerous complex medical, social and emotional challenges that present. Declines in quality of life and disease-related symptoms have been observed [4-6]. However, the physical status of this population remains unclear. For example, habitual physical activity levels in individuals with metastatic disease has not been previously described.

Women with metastatic cancer may be open to the idea of undertaking increased daily physical activity or structured exercise to improve their physical and psychosocial well-being. For instance, a cross-sectional study of community-dwelling palliative care patients reported that $>90 \%$ were interested in participating in a physical activity program [7]. However, consideration is required to identify what barriers to greater activity participation may exist as well as the impact of their physical impairments. Barriers to participation in physical activity have not been explored in women living with metastatic breast cancer; however, it has been explored in a large cross-sectional study of persons treated for cancer, with stages ranging from I to IV. The five most common barriers that interfered with exercise participation were illness, joint stiffness, fatigue, pain and lack of motivation [8]. Physical impairments have been documented in women with metastatic breast cancer, with $92 \%$ of the population reporting to have at least one physical impairment, and almost 
$50 \%$ a limitation in muscle strength [9]. Such existing impairments coupled with multidimensional barriers may impact on one's ability to carry out physical activity.

Physical activity promotion has become a focus of cancer rehabilitation therapy and research. Its effect on treatment-related side-effects and quality of life in women with early stage breast cancer has been extensively documented [10-12]. Conversely, women with metastatic breast cancer have traditionally been excluded from physical activity interventions due to fear of pathological bone fracture and cancer-related fatigue, which is a persistent, subjective sense of tiredness related to cancer or cancer treatment that interferes with usual functioning [12-14]. However, a number of pilot and case series studies suggest that this group may experience appreciable physical and psychosocial benefits from increased levels of physical activity, including reduced fatigue, lower symptoms of dyspnoea and improved physical function $[15,16]$. In order to deliver an appropriately-designed exercise program, it is necessary to understand the current physical capabilities of this population.

The aims of this study were therefore to determine the level of physical activity, fitness, and patient-reported outcomes in women with metastatic breast cancer compared to similarly aged healthy controls, as well as to explore the medical, demographic, patient-reported outcome and physical factors associated with physical activity.

\section{METHODS}

\section{Participants}

Two groups of women were recruited: i) women with metastatic breast cancer $(n=71)$ and ii) women with no history of cancer $(n=71)$. Women with metastatic disease were recruited from the outpatient departments of six metropolitan cancer centres in Sydney. Eighty-one women were invited to participate in the study by their oncologist or breast nurse during a routine clinic visit. 
Women were eligible if they had been diagnosed with metastatic breast cancer, were able to communicate in English and in whom the oncologist expected survival of at least 6 months. Participants also had to be living in the community and ambulatory, defined by an Eastern Cooperative Oncology Group (ECOG) performance status of 0-3 [17].

Women with no history of cancer were recruited through internal advertising at The University of Sydney and via Register4, an online community for breast cancer research volunteers in Australia. Women were eligible if they had never had cancer, were living in the community and ambulatory, and able to communicate in English.

Participants in both groups were screened for cardiovascular, neurological and musculoskeletal risk factors using the Physical Activity Readiness Questionnaire (PAR-Q) [18]. Participants in whom medical evaluation was indicated discussed the study in detail with their oncologist or primary care physician to gain medical clearance (Physical Activity Readiness Medical Examination; PARmed$X[18])$ prior to enrolling in the study.

The study was approved by the Human Research Ethics Committee at each of the institutions where women were recruited, and all participants provided written informed consent.

\section{Protocol}

Assessments were undertaken in the participant's home or at another convenient location.

Background information including medical history and medications were recorded. Measurements of stature, body mass, muscular strength, aerobic fitness and daily physical activity were obtained. As field tests of physical fitness have not been validated in women with metastatic breast cancer, tests validated in similarly aged populations were selected. Patient-reported outcomes (PROs) were obtained from self-report questionnaires. A standardised protocol was implemented whereby 
participants were asked to rest for 10-15 minutes between the various physical assessments.

Following these measurements, the participant wore a SenseWear® physical activity monitor for one week. Participants were instructed to maintain their usual activities throughout the monitoring period.

\section{Measurements}

\section{Physical Activity Assessment}

Physical activity was determined from the Godin Leisure-Time Exercise Questionnaire (GLTEQ) [19] and from a physical activity monitor. The GLTEQ is a robust measure used to quantify physical activity $[20,19]$ and is commonly used to assess physical activity in cancer patients [2123] . It is a simple measure that uses self-recall to quantify the frequency of vigorous, moderate and light intensity physical activities performed for more than 15 minutes at a time, during a typical week. These frequencies were computed to give a total leisure-time activity score.

Participants were asked to wear a SenseWear® armband (BodyMedia Inc., Pittsburgh, USA) [2426] for all waking hours, except during water-based activities, for a period of 7 consecutive days. The SenseWear® is a physical activity monitor worn over the triceps brachii muscle of the arm and is designed to capture typical activities of daily life including standing, sitting, walking, running and cycling. The device continuously samples physiological parameters including heat flux, galvanic skin response, skin temperature and near-body ambient temperature, and includes a 2-axis accelerometer. Data from these sensors are combined with gender, age, body mass and stature to estimate daily energy expenditure and amount of physical activity performed (SenseWear® Professional Software, version 7.0, BodyMedia Inc., Pittsburgh, PA, USA). The SenseWear® has been shown to be highly reliable [27] and valid for use in healthy adults, with intraclass correlations of 0.80 to a gold standard for energy expenditure $[26,24]$. Variables calculated from the SenseWear® include time spent in moderate-to-vigorous intensity physical activity (MVPA) and 
steps taken per day (steps/day). Time spent in MVPA was determined using a criterion threshold $\geq 3$ METs [28].

\section{Fitness Assessment}

Aerobic fitness was estimated using the Modified Canadian Aerobic Fitness Test (mCAFT) [29-31]. Participants were required to complete one or more 3-minute stages of stepping up and down on a two-step bench. Following completion of each stepping session, heart rate was recorded using a heart rate monitor (FT4, Polar Electro Oy, Finland). If a participant did not reach the desired heart rate, the participant proceeded to the next-more-demanding stepping stage. Sessions continued until the participant's heart rate exceeded $85 \%$ of age-predicted maximal heart rate. The stepping cadence and duration of each exercise stage was regulated using music provided with the mCAFT protocol. Aerobic fitness was reported as $\mathrm{VO}_{2 \max }$, predicted from mCAFT equations which have been validated in a healthy adult population [29]. $\mathrm{VO}_{2 \max }$ for each participant was then compared to population normative values [32].

Handgrip strength was measured using hand dynamometry (Jamar Plus+; Sammons Preston Rolyon, Bolingbrook, USA) [33]. Hand dynamometry has been shown to have excellent test-retest reliability in many studies, with intraclass correlation coefficient values ranging between 0.81 and 0.98 [34-36]. With the participant standing with feet hip distance apart, toes pointing forward and eyes looking straight ahead, participants grasped the dynamometer between the fingers and the palm at the base of the thumb. The dynamometer was held in line with the forearm at the level of the thigh with the arm slightly abducted so that it is not touching the body [31]. The participants were instructed to squeeze the handgrip as forcefully as possible to generate maximal force, performing at least three trials on each hand. The maximal absolute handgrip strength (HandGrip strength ${ }_{\mathrm{ABS}}$ ) of the dominant limb was used for analysis. 
Lower limb strength was measured using a back-leg dynamometer (Back-D; Takei Kiki Kogyo, Tokyo, Japan) [37]. Information on the reliability of such dynamometers is limited, however one study observed significant correlation coefficients $(r=0.80)$ when examining test and retest measures [37]. Participants stood on the foot-plate, with the scapulae and buttocks positioned flat against a wall. Participants flexed the legs until the knee extension angle was between $130-140^{\circ}$, and then reached down with elbows fully extended. The pull-bar of the dynamometer was placed in the hands and the chain length adjusted. Participants were instructed to extend the legs with maximal effort, pulling the bar simultaneously. At least three trials were performed, and the highest

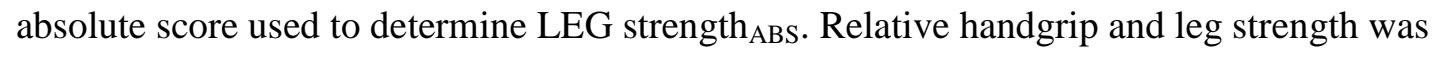
determined by dividing HandGrip strength ${ }_{\mathrm{ABS}}$ and LEG strength $\mathrm{ABS}_{\mathrm{BS}}$ by the participant's body mass to derive HandGrip strength $\mathrm{REL}_{\text {and }}$ aEG strength ${ }_{\mathrm{REL}}$ to account for participants of different stature [38].

\section{Patient-Reported Outcomes}

The 30-item European Organisation for Research and Treatment of Cancer Quality of Life Questionnaire (EORTC QLQ-30) [39, 40] was used, whereby items relating to five dimensions of functioning are rated: physical, role, social, emotional and cognitive. In addition, a range of items relating to symptoms are rated: fatigue, nausea and vomiting, pain, dyspnoea, insomnia, appetite loss, constipation and diarrhoea. This questionnaire has been used extensively in cancer patients with reliabilities ranging from 0.69 to 0.90 across the various dimensions and symptoms. A higher

score for a functional scale represents better well-being whereas a higher score for a symptom scale represents a higher burden of symptomology. For analysis, function scales and symptoms were considered independently.

The Functional Assessment of Chronic Illness Therapy: Fatigue (FACIT-F) was used to assess the severity and impact of fatigue $[41,42]$. The FACIT-F was originally designed to measure cancer 
fatigue and is commonly used in this population $[43,44]$. The maximum score is 52 , with a lower score indicative of more significant fatigue.

The Life Space Assessment (LSA) was used to assess mobility based on the distance a person reports moving during the preceding 4 week period [45-47]. The LSA has demonstrated to have excellent test-retest reliability with an intraclass coefficient of 0.96 [45]. Questions establish movement to specific life-spaces ranging from within one's home to beyond one's town. Specific levels are assessed by asking: "During the past 4 weeks, have you been to other rooms of your home besides the room where you sleep; to an area outside your home such as your porch, deck or patio, hallway of an apartment building, or garage; to places in your neighborhood, other than your own yard or apartment building; to places outside your neighborhood but within your town; and to places outside your town?" For each level, participants are asked how many days within a week they attained that level, and whether they required help from equipment or another person. The scores for this questionnaire range from 0 to 120 , with a higher score representative of a higher pattern of mobility.

\section{Statistical Analyses}

Independent t-tests were used to assess differences between the metastatic and healthy groups on continuous variables. These comparisons were repeated using regression modelling that adjusted for age and BMI as part of a sensitivity analysis. Multiple regression was used to determine if any of the demographic, fitness or PRO variables (as reported in Table 2) were related to MVPA and steps/day. Candidates for inclusion in each initial multivariate model comprised those variables that attained $\mathrm{P}<0.25$ on univariate analysis. A backwards elimination approach from each initial model was used to progressively eliminate covariates that were not statistically significant at the 0.05 level. Variables were tested for collinearity and only non-related variables retained. Adequacy of the final model was assessed by examination of residuals. Means and standard deviations are 
presented unless otherwise stated. Statistical analyses were performed using IBM SPSS Version 20 for Windows (IBM Corp. Somers, NY).

\section{RESULTS}

Women with metastatic disease were aged 57.7 (9.5) y and healthy controls aged 55.0 (9.4) y. The body mass index (BMI) of the metastatic group was 27.3 (5.9) $\mathrm{kg} \cdot \mathrm{m}^{-2} \mathrm{vs} .25 .0$ (4.4) $\mathrm{kg} \cdot \mathrm{m}^{-2}$ for the healthy group. Of those with breast cancer, the median and inter-quartile range for time since metastatic disease onset was 1.5 y (1.0 to $4.0 \mathrm{y}$; Table 1$)$. Twenty-seven women had metastases to both bone and viscera (38\%), 25 to viscera-only (35\%), and 19 to bone-only (27\%). Forty-nine percent of women were receiving chemotherapy and $45 \%$ receiving hormone therapy.

All women in the healthy group completed the physical assessments; however, not all of the metastatic group were able to do so. Of the 71 women with metastatic cancer, 53 (i.e. $75 \%$ ) completed all physical components of the study. Eight completed only PROs and physical activity monitoring, being unable to complete fitness testing for a variety of reasons, including living too far from the testing sites $(n=3)$, undiagnosed hypertension $(n=2)$, dyspnoea $(n=2)$ and neuropathy $(n=1)$. The remaining women $(n=10)$ were able to complete either strength or aerobic testing, but not both. Reasons for being unable to complete both components included disease or treatmentrelated factors such as severe lymphedema $(n=1)$ and biomechanical limitations as a result of hip or knee replacements $(n=3)$. Other reasons included restrictions expected in an older population such as arthritic pain $(n=2)$, balance concerns $(n=1)$ and cardiac issues $(n=3)$. Notably, no adverse events occurred in those who were able to complete the assessments. 


\section{Levels of Physical Activity}

The women with metastatic cancer were significantly less active, attaining only $56 \%$ of steps/day (5434 (3174) vs. 9635 (3327) steps/day, $P<0.001$ ) of their healthy counterparts (Fig 1). The metastatic group also spent a significantly lower duration engaged in MVPA (82 (78) vs. 142 (82) minutes, respectively<0.001).

\section{Levels of Aerobic Fitness and Muscle Strength}

Women with metastatic disease had a significantly lower estimated $\mathrm{VO}_{2 \max }$ than the healthy women (Fig $1 ; 25.3(5.4)$ vs. $\left.31.9(6.1) \mathrm{ml} \bullet \mathrm{kg}^{-1} \bullet \mathrm{min}^{-1}, P<0.001\right)$. More healthy women had a predicted $\mathrm{VO}_{2 \max }$ above average for their age, based on population-normative values, compared to the metastatic group ( $81 \%$ vs. $37 \%, P<0.001)$. In addition, the metastatic group were also significantly weaker with respect to absolute and relative strength measures. LEG strength ${ }_{\mathrm{ABS}}$ for the metastatic and healthy groups was $53.5(23.7)$ vs. $76.0(27.4) \mathrm{kg}(P<0.001)$, and LEG strength REL $_{\text {was }} 0.76$

(0.31) vs. $1.15(0.45) \mathrm{kg} \mathrm{kg}^{-1}$, respectively $(P<0.001)$. HandGrip strength ${ }_{\mathrm{ABS}}$ was $26.6(6.0)$ vs. 30.2 (6.4) $\mathrm{kg}(P=0.001)$ and HandGrip strength REL $_{\text {was }} 0.38(0.09)$ vs. $0.46(0.11) \mathrm{kg}^{\circ} \mathrm{kg}^{-1}$, respectively $(P<0.001)$. Further analysis revealed these results were insensitive to adjustment for age and BMI.

\section{Patient-Reported Outcomes (PROs)}

FACIT-F demonstrated that fatigue was significantly higher in women with metastatic cancer compared to their healthy counterparts $(38.0$ (9.8) vs. 46.3 (4.6), $P<0.001)$ (Table 2). Women with metastatic disease scored lower in all functional domains of the EORTC QLQ-30 $(P<0.001)$ and were also more symptomatic, reporting higher levels of nausea, pain, dyspnoea, appetite loss, constipation and diarrhoea $(P<0.05)$. The between-group comparisons of physical activity, fitness and PROs did not change significantly when adjusting for age and BMI. 


\section{Relationships with Physical Activity}

Table 3 reveals the variables that were predictors of physical activity, with no strong evidence that having metastatic disease alters these associations. HandGrip and LEG strength $\mathrm{REL}, \mathrm{VO}_{2 \max }$, body mass and BMI were significantly related to MVPA $(P<0.001)$. A number of fitness indicators and PROs were related to steps/day, including HandGrip and LEG strength REL $_{\text {VO }} \mathrm{VO}_{2 \max }$, FACIT-Fatigue, appetite loss and physical function $(P<0.05)$.

Steps/day was significantly related to physical function, pain, age, $\mathrm{BMI}, \mathrm{VO}_{2 \max }$ and LEG strength $_{\text {REL }}$. This regression model explained $42 \%$ of the variance $(P<0.001)$. MVPA was

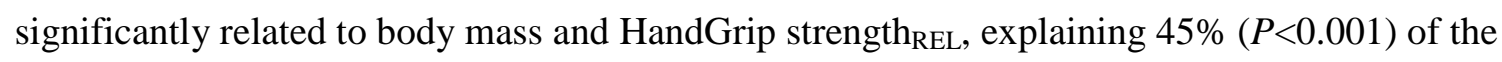
variance. Notably, having metastatic disease did not explain either of these models. For both of these models, some data were missing for a variety of reasons, as outlined above, so these findings should be interpreted with some caution.

\section{DISCUSSION}

The aim of this study was to develop an understanding of the physical activity and fitness of women with metastatic breast cancer. Women with metastatic disease, while overall of lower fitness than a similarly aged healthy cohort, were able to participate in this study. Interestingly, some women with metastatic disease exceeded the fitness and walking capacity of women without cancer, indicating a wide range of physical abilities.

As expected, the metastatic group displayed significantly decreased aerobic fitness and strength compared to the healthy group. Aerobic fitness in the metastatic group was, on average, $21 \%$ lower than healthy controls. Notably, when aerobic fitness was presented as age-adjusted normative scores [32], many in the metastatic group outperformed their healthy peers, including twenty women who exceeded the average fitness band for their age. Furthermore, all women with metastatic disease who were able to undergo aerobic fitness assessment demonstrated $\mathrm{VO}_{2}$ peak values greater than 
that required for functional independence, i.e. $15 \mathrm{ml} \bullet \mathrm{kg}^{-1} \cdot \mathrm{min}^{-1}[48,49]$. These findings suggest that limitations to participation in aerobic type activities are not a consequence of reduced aerobic fitness. For those unable to perform activities of daily living, other factors such as pain, fatigue, comorbidities and strength need to be considered.

Previous research reported women with metastatic breast cancer possess aerobic fitness, on average, $33 \%$ less than healthy sedentary women [23], larger than the $21 \%$ difference in this study. Possible explanations for this discrepancy may include the use of a sub-maximal, home-based, aerobic steptest in this study. Although the mCAFT has been validated [29], the risk of under- or overestimating $\mathrm{VO}_{2 \max }$ increases as compared to completing a maximal aerobic assessment in a laboratory [23]. Another possible explanation is a response-bias in participant selection. All women recruited to the aforementioned study [23] were receiving some form of cytotoxic chemotherapy. However, in the current study, only $49 \%$ of women were undergoing chemotherapy.

Not surprisingly, our findings revealed that the metastatic group also experienced significantly lower functioning across all domains, and higher symptomology when compared to their healthy peers. It has been suggested that interventions designed to address clusters of symptoms, such as the combination of fatigue, nausea, decreased appetite and dyspnoea [6], may be more efficacious than those targeting individual symptoms. To date, the role of physical activity to address this symptom cluster has not been explored. However, as fatigue, in particular, is reduced with increased physical activity [50], the role of regular exercise is worth exploring.

Despite presenting with poor quality of life, the metastatic group in this study reported higher functioning and less symptomology compared to other studies of women living with metastatic cancer $[51,23]$. This may be explained by the potential difference in participant characteristics and treatment regimens in such a heterogeneous population. For example, a large percentage of our 
cohort have metastases confined to bone, for which median survival is longer compared to those with visceral disease. This more indolent disease course is often treated with less aggressive treatment and patients generally have fewer symptoms [52]. It was surprising the level of function demonstrated by this cohort of women with metastatic disease, particularly that many were above average fitness of women without cancer of the same age. In addition, many women presented with mild or no symptoms related to their cancer. For this cohort of women, symptoms and physical capacity may be less of a barrier to being physically active compared to the general metastatic breast cancer population.

The metastatic group were significantly more sedentary, achieving only $56 \%$ of steps/day and $58 \%$ of MVPA compared to the healthy group (Fig 1). Several fitness indicators and symptoms were associated with physical activity, although there was no strong evidence that having metastatic disease contributed significantly. When the healthy and metastatic groups were combined, a range of outcomes including higher levels of physical function, aerobic fitness and Leg strength $\mathrm{REL}_{\mathrm{R}}$, low levels of pain, low BMI and being younger explained higher daily step counts. MVPA was

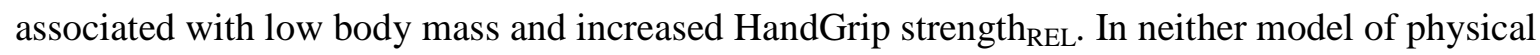
activity did having metastatic disease contribute significantly. This reiterates that these women with metastatic cancer, whilst deconditioned, did not appear to be significantly debilitated by their disease.

The physical limitations experienced by women with metastatic disease could potentially be improved through physical activity programs. Those who were least active demonstrated low levels of aerobic fitness and strength. A program incorporating both of these aspects could address these underlying impairments. As persons with metastatic cancer have historically been encouraged to rest, there have been few investigations into the impact of structured exercise or lifestyle physical activity interventions in this population. Whilst minimal evidence is currently available, pilot 
interventions suggest that physical activity has the capacity to decelerate the decline in physical performance in metastatic cancer patients, with the potential to improve or maintain mobility and independence in daily life $[15,16]$. Research examining physical activity preferences in patients with metastatic disease found that $84 \%$ of patients would be interested in a program that could be conducted at home, and $72 \%$ reported walking as their preference [7]. As such, a starting point for this population might be the implementation of a walking program. In our cohort, the median steps/day was 4655 , with only $15 \%$ achieving > 8000 steps/day, the level at which most health benefits are achieved in older populations [53]. However, as physical activity levels vary extensively in this population, a patient-specific approach with individualised guidance is recommended. Whether structured exercise programs or lifestyle physical activity interventions are more clinically efficacious for health and quality of life in this population is currently unclear.

Although this study has many strengths, there were also a few limitations. It is likely that women in this study were higher functioning as compared to the average metastatic population. With its focus on physical activity, it is possible that there was a response-bias in both groups whereby those with a particular interest in their personal fitness, higher physical abilities or a keenness to participate volunteered for the study. For practical purposes, robust field measures were used to assess physical fitness in both groups in place of gold standard laboratory measures. Another limitation relates to the potential underestimation of physical activity due to activities not captured via the SenseWear® armband, such as cycling or swimming.

In summary, individuals with metastatic breast cancer possessed reduced aerobic fitness, lower strength and more sedentary physical activity levels compared with age-matched healthy controls. They also experienced poorer functioning and higher symptom burden. Although those with metastatic cancer experienced such deficits, the population examined in this study were still capable of functioning independently and should be encouraged to be physically active. Whilst structured 
exercise and lifestyle physical activity interventions have previously focused on women with earlystage breast cancer, this research identifies a need to investigate the potential benefits for women living with metastatic disease.

\section{Acknowledgements}

This project was supported by a grant from National Breast Cancer Foundation, Australia. SLK is a National Breast Cancer Foundation Career Research Fellow. We like to acknowledge Register4 for assistance with recruitment and The Primary Care Collaborative Cancer Clinical Trials Groups for assistance in design.

\section{Conflict of Interest}

The authors declare that they have no conflict of interest. 


\section{References}

1. Australian Institute of Health and Welfare \& Australiasian Association of Cancer Registries 2012. Cancer in Australia: an overview, 2012. Cancer Series. 2012;no 74(Cat. no. CAN 70):Canberra: AIHW.

2. Lord SJ, Marinovich ML, Patterson JA, Wilcken N, Kiely BE, Gebski V et al. Incidence of metastatic breast cancer in an Australian population-based cohort of women with non-metastatic breast cancer at diagnosis. Med J Aust. 2012;196(11):688-92.

3. Tracey EA BH, Chen W, Baker D, Roder D, Jelfs P \& Bishop Survival from cancer in NSW: 1980 to 2003. Sydney: Cancer Institute NSW. 2007.

4. Meisel JL, Domchek SM, Vonderheide RH, Giobbie-Hurder A, Lin NU, Winer EP et al. Quality of life in long-term survivors of metastatic breast cancer. Clin Breast Cancer. 2012;12:119-26.

5. Reed E, Simmonds P, Haviland J, Corner J. Quality of life and experience of care in women with metastatic breast cancer: a cross-sectional survey. J Pain Symptom Manage. 2012;43:747-58.

6. Cheung WY, Le LW, Zimmermann C. Symptom clusters in patients with advanced cancers. Support Care Cancer. 2009;17:1223-30.

7. Lowe SS, Watanabe SM, Baracos VE, Courneya KS. Physical activity interests and preferences in palliative cancer patients. Support Care Cancer. 2010;18:1469-75.

8. Blaney JM, Lowe-Strong A, Rankin-Watt J, Campbell A, Gracey JH. Cancer survivors' exercise barriers, facilitators and preferences in the context of fatigue, quality of life and physical activity participation: a questionnaire-survey. Psychooncology. 2013;22:186-94.

9. Cheville AL, Troxel AB, Basford JR, Kornblith AB. Prevalence and treatment patterns of physical impairments in patients with metastatic breast cancer. J Clin Oncol. 2008;26:2621-9.

10. Cramp F, Daniel J. Exercise for the management of cancer-related fatigue in adults. Cochrane Database Syst Rev. 2008(2):CD006145.

11. Speck RM, Courneya KS, Masse LC, Duval S, Schmitz KH. An update of controlled physical activity trials in cancer survivors: a systematic review and meta-analysis. J Cancer Surviv. 2010;4:87-100.

12. Adamsen L, Quist M, Andersen C, Moller T, Herrstedt J, Kronborg D et al. Effect of a multimodal high intensity exercise intervention in cancer patients undergoing chemotherapy: randomised controlled trial. BMJ. 2009;339:b3410.

13. Courneya KS, McKenzie DC, Mackey JR, Gelmon K, Friedenreich CM, Yasui Y et al. Effects of Exercise Dose and Type During Breast Cancer Chemotherapy: Multicenter Randomized Trial. J Natl Cancer Inst. 2013;105:1821-32.

14. Mock V. Evidence-based treatment for cancer-related fatigue. J Natl Cancer Inst Monogr. 2004(32):112-8.

15. Oldervoll LM, Loge JH, Paltiel H, Asp MB, Vidvei U, Wiken AN et al. The effect of a physical exercise program in palliative care: A phase II study. J Pain Symptom Manage. 2006;31:421-30.

16. Headley JA, Ownby KK, John LD. The effect of seated exercise on fatigue and quality of life in women with advanced breast cancer. Oncol Nurs Forum. 2004;31:977-83. 
17. Oken MM, Creech RH, Tormey DC, Horton J, Davis TE, McFadden ET et al. Toxicity and response criteria of the Eastern Cooperative Oncology Group. Am J Clin Oncol. 1982;5:649-55.

18. Thomas S, Reading J, Shephard RJ. Revision of the Physical Activity Readiness Questionnaire (PAR-Q). Can J Sport Sci. 1992;17:338-45.

19. Godin G, Shephard RJ. A simple method to assess exercise behavior in the community. Can J Appl Sport Sci. 1985;10:141-6.

20. Gionet N, Godin G. Self-Reported Exercise Behavior of Employees: A Validity Study. J Occup Med. 1989;31:969-73.

21. Courneya KS, Segal RJ, Mackey JR, Gelmon K, Reid RD, Friedenreich CM et al. Effects of aerobic and resistance exercise in breast cancer patients receiving adjuvant chemotherapy: a multicenter randomized controlled trial. J Clin Oncol. 2007;25:4396-404.

22. Courneya KS, Friedenreich CM, Sela RA, Quinney HA, Rhodes RE, Handman M. The group psychotherapy and home-based physical exercise (group-hope) trial in cancer survivors: physical fitness and quality of life outcomes. Psychooncology. 2003;12:357-74.

23. Jones LW, Courneya KS, Mackey JR, Muss HB, Pituskin EN, Scott JM et al. Cardiopulmonary function and age-related decline across the breast cancer survivorship continuum. J Clin Oncol. 2012;30:2530-7.

24. St-Onge M, Mignault D, Allison DB, Rabasa-Lhoret R. Evaluation of a portable device to measure daily energy expenditure in free-living adults. Am J Clin Nutr. 2007;85:742-9.

25. Mackey DC, Manini TM, Schoeller DA, Koster A, Glynn NW, Goodpaster BH et al. Validation of an armband to measure daily energy expenditure in older adults. J Gerontol (A Biol Sci Med Sci). 2011;66:1108-13.

26. Johannsen DL, Calabro MA, Stewart J, Franke W, Rood JC, Welk GJ. Accuracy of armband monitors for measuring daily energy expenditure in healthy adults. Med Sci Sports Exerc.

2010;42:2134-40.

27. Brazeau AS, Karelis AD, Mignault D, Lacroix MJ, Prud'homme D, Rabasa-Lhoret R. Testretest reliability of a portable monitor to assess energy expenditure. Appl Physiol Nutr Metab. 2011;36:339-43.

28. Haskell WL, Lee IM, Pate RR, Powell KE, Blair SN, Franklin BA et al. Physical activity and public health: updated recommendation for adults from the American College of Sports Medicine and the American Heart Association. Med Sci Sports Exerc. 2007;39:1423-34.

29. Weller IM, Thomas SG, Gledhill N, Paterson D, Quinney A. A study to validate the modified Canadian Aerobic Fitness Test. Can J Appl Physiol. 1995;20:211-21.

30. Weller IM, Thomas SG, Corey PN, Cox MH. Prediction of maximal oxygen uptake from a modified Canadian aerobic fitness test. Can J Appl Physiol. 1993;18:175-88.

31. Physiology CSfE. Canadian Physical Activity, Fitness and Lifestyle Approach (CPAFLA). 3rd Edition ed. Ottawa: 2003.

32. Pescatello L, Arena R, Riebe D, Thompson P. ACSM's Guidelines for Exercise Testing and Prescription. 9th ed. Philadelphia: Lippincott, Williams and Wilkins; 2014. 
33. Abizanda P, Navarro JL, Garcia-Tomas MI, Lopez-Jimenez E, Martinez-Sanchez E, Paterna G. Validity and usefulness of hand-held dynamometry for measuring muscle strength in communitydwelling older persons. Arch Gerontol Geriatr. 2012;54:21-7.

34. Savva C, Giakis G, Efstathiou M, Karagiannis C. Test-Retest Reliability of Handgrip Strength Measurement Using a Hydraulic Hand Dynamometer in Patients With Cervical Radiculopathy. J Manipulative Physiol Ther. 2014;37:206-10.

35. Peolsson A, Hedlund R, Oberg B. Intra- and inter-tester reliability and reference values for hand strength. J Rehabil Med. 2001;33:36-41.

36. Savva C, Karagiannis C, Rushton A. Test-retest reliability of grip strength measurement in full elbow extension to evaluate maximum grip strength. J Hand Surg Eur Vol. 2013;38:183-6.

37. Coldwells A, Atkinson G, Reilly T. Sources of variation in back and leg dynamometry. Ergonomics. 1994;37:79-86.

38. Chandrasekaran B, Ghosh A, Prasad C, Krishnan K, Chandrasharma B. Age and anthropometric traits predict handgrip strength in healthy normals. J Hand Microsurg. 2010;2:58-61.

39. Aaronson NK, Ahmedzai S, Bergman B, Bullinger M, Cull A, Duez NJ et al. The European Organization for Research and Treatment of Cancer QLQ-C30: a quality-of-life instrument for use in international clinical trials in oncology. J Natl Cancer Inst. 1993;85:365-76.

40. Hjermstad MJ, Fossa SD, Bjordal K, Kaasa S. Test/retest study of the European Organization for Research and Treatment of Cancer Core Quality-of-Life Questionnaire. J Clin Oncol. 1995;13:1249-54.

41. Yellen SB, Cella DF, Webster K, Blendowski C, Kaplan E. Measuring fatigue and other anemia-related symptoms with the Functional Assessment of Cancer Therapy (FACT) measurement system. J Pain Symptom Manage. 1997;13:63-74.

42. Webster K, Cella D, Yost K. The Functional Assessment of Chronic Illness Therapy (FACIT) Measurement System: properties, applications, and interpretation. Health Qual Life Outcomes. 2003;1:79.

43. Cella D, Lai JS, Chang CH, Peterman A, Slavin M. Fatigue in cancer patients compared with fatigue in the general United States population. Cancer. 2002;94:528-38.

44. Butt Z, Lai JS, Rao D, Heinemann AW, Bill A, Cella D. Measurement of fatigue in cancer, stroke, and HIV using the Functional Assessment of Chronic Illness Therapy - Fatigue (FACIT-F) scale. J Psychosom Res. 2013;74:64-8.

45. Baker PS, Bodner EV, Allman RM. Measuring life-space mobility in community-dwelling older adults. J Am Geriatr Soc. 2003;51:1610-4.

46. Peel C, Sawyer Baker P, Roth DL, Brown CJ, Brodner EV, Allman RM. Assessing mobility in older adults: the UAB Study of Aging Life-Space Assessment. Phys Ther. 2005;85:1008-119.

47. Phillips JL, Lam L, Luckett T, Agar M, Currow D. Is the Life Space Assessment Applicable to a Palliative Care Population? Its Relationship to Measures of Performance and Quality of Life. J Pain Symptom Manage. 2013. doi: 10.1016/j.jpainsymman.2013.06.017 
48. Paterson DH, Cunningham DA, Koval JJ, St Croix CM. Aerobic fitness in a population of independently living men and women aged 55-86 years. Med Sci Sports Exerc. 1999;31:1813-20.

49. Shephard R. Physical Activity and Aging. London: Croom-Helm; 1987.

50. Cramp F, Byron-Daniel J. Exercise for the management of cancer-related fatigue in adults. Cochrane Database Syst Rev. 2012;11:CD006145.

51. Efficace F, Biganzoli L, Piccart M, Coens C, Van Steen K, Cufer T et al. Baseline health-related quality-of-life data as prognostic factors in a phase III multicentre study of women with metastatic breast cancer. Eur J Cancer. 2004;40:1021-30.

52. Niikura N, Liu J, Hayashi N, Palla SL, Tokuda Y, Hortobagyi GN et al. Treatment outcome and prognostic factors for patients with bone-only metastases of breast cancer: a single-institution retrospective analysis. Oncologist. 2011;16:155-64.

53. Ewald B, Attia J, McElduff P. How Many Steps are Enough? Dose Response Curves for Pedometer Steps and Multiple Health Markers in a Community Based Sample of Older Australians. J Phys Act Health. 2014;11:509-518. 


\section{Figure Legends:}

Figure 1. Comparison of the metastatic group with the healthy group on physical activity and fitness measures. Mean and standard deviation are shown. * denotes significant between-group difference $(\mathrm{p}<0.05)$. 
Table 1. Medical characteristics of the metastatic cancer group

\begin{tabular}{|c|c|}
\hline & $\mathrm{n}=71$ \\
\hline Time since primary $B C$ diagnosis (y; mean (SD)) & $7.8(5.5)$ \\
\hline Time since MET diagnosis ( $\mathrm{y}$; mean (SD)) & $2.9(3.1)$ \\
\hline Time between primary BC and MET diagnosis ( $\mathrm{y}$; mean (SD)) & $5.0(5.0)$ \\
\hline \multicolumn{2}{|l|}{ ECOG (\%) } \\
\hline 0 & 54 \\
\hline 1 & 29 \\
\hline 2 & 12 \\
\hline 3 & 4 \\
\hline \multicolumn{2}{|l|}{ Location of Metastasis (\%) } \\
\hline Bone Only & 27 \\
\hline Visceral Only & 35 \\
\hline Bone and Visceral & 38 \\
\hline \multicolumn{2}{|l|}{ Current Treatment (\%) } \\
\hline Hormone Therapy & 45 \\
\hline Chemotherapy: Oral & 28 \\
\hline Chemotherapy: IV & 21 \\
\hline Trastuzumab & 17 \\
\hline No current treatment & 6 \\
\hline Lapatinib & 3 \\
\hline Radiotherapy & 0 \\
\hline \multicolumn{2}{|l|}{ Lymphoedema (\%) } \\
\hline Present & 20 \\
\hline
\end{tabular}

"BC" denotes breast cancer; "MET" denotes metastatic breast cancer 
Table 2. Comparison of demographics, physical measures and patient-reported outcomes between women living with metastatic breast cancer and healthy women.

\begin{tabular}{|c|c|c|c|c|}
\hline & $\begin{array}{l}\text { Metastatic } \\
n=71^{*} \\
\text { mean (SD) }\end{array}$ & $\begin{array}{c}\text { Healthy } \\
n=71 \\
\text { mean (SD) }\end{array}$ & $\begin{array}{c}\text { Between-group } \\
\text { difference }(95 \% \mathrm{Cl})\end{array}$ & $P$ \\
\hline Age (y) & $57.7(9.5)$ & $55.0(9.4)$ & $-2.7(-5.8$ to 0.4$)$ & 0.091 \\
\hline Height (m) & $1.63(0.07)$ & $1.64(0.06)$ & $0.01(-0.02$ to 0.03$)$ & 0.605 \\
\hline Body mass (kg) & 72.7 (16.9) & $67.1(12.5)$ & $-5.6(-10.5$ to -0.7$)$ & 0.027 \\
\hline $\mathrm{BMI}\left(\mathrm{kg} \cdot \mathrm{m}^{-2}\right)$ & $27.3(5.9)$ & $25.0(4.4)$ & $-2.3(-4.0$ to -0.5$)$ & 0.010 \\
\hline \multicolumn{5}{|l|}{ Physical Fitness } \\
\hline $\mathrm{VO}_{2 \max }\left(\mathrm{ml} \cdot \mathrm{kg}^{-1} \cdot \mathrm{min}^{-1}\right)$ & $25.3(5.4)$ & $31.9(6.1)$ & 6.6 (4.5 to 8.7$)$ & $<0.001$ \\
\hline HandGrip Strength ${ }_{\mathrm{ABS}}(\mathrm{kg})$ & $26.6(6.0)$ & $30.2(6.4)$ & 3.6 (1.4 to 5.8$)$ & 0.001 \\
\hline HandGrip Strength ${ }_{\text {REL }}\left(\mathrm{kg} \bullet \mathrm{kg}^{-1}\right)$ & $0.38(0.09)$ & $0.46(0.11)$ & 0.08 (0.04 to 1.11$)$ & $<0.001$ \\
\hline LEG Strength ${ }_{\mathrm{ABS}}(\mathrm{kg})$ & $53.5(23.7)$ & $76.0(27.4)$ & 22.5 (13.6 to 31.4$)$ & $<0.001$ \\
\hline LEG Strength $h_{\text {REL }}\left(\mathrm{kg} \bullet \mathrm{kg}^{-1}\right)$ & $0.76(0.31)$ & $1.15(0.45)$ & 0.39 (0.26 to 0.53$)$ & $<0.001$ \\
\hline \multicolumn{5}{|l|}{ Physical Activity } \\
\hline Steps/day & $5434(3174)$ & $9635(3327)$ & 4200 (3088 to 5313 ) & $<0.001$ \\
\hline $\mathrm{MVPA}^{ \pm}$ & $82(78)$ & $142(82)$ & 63 (36 to 91) & $<0.001$ \\
\hline GLTEQ & $23.6(20.6)$ & $54.1(30.7)$ & 30.5 (21.9 to 39.2$)$ & $<0.001$ \\
\hline Life Space & $77.2(23.0)$ & $90.1(13.5)$ & 12.9 (6.6 to 19.2$)$ & $<0.001$ \\
\hline FACIT-Fatigue & $38.0(9.8)$ & $46.3(4.6)$ & 8.3 (5.8 to 10.8 ) & $<0.001$ \\
\hline \multicolumn{5}{|l|}{ EORTC QLQ-C30 } \\
\hline \multicolumn{5}{|l|}{ Function Scales } \\
\hline Global Health & $70.8(20.4)$ & $81.7(15.0)$ & 10.9 (5.0 to 16.9$)$ & $<0.001$ \\
\hline Physical & $78.4(17.4)$ & $95.0(8.5)$ & 16.6 (12.1 to 21.2 ) & $<0.001$ \\
\hline Role & $79.8(23.7)$ & $95.5(10.1)$ & 15.7 (9.6 to 21.8 ) & $<0.001$ \\
\hline Emotional & 78.5 (19.9) & $85.9(12.4)$ & 7.4 (1.9 to 12.9 ) & 0.009 \\
\hline Cognitive & $84.3(15.1)$ & $91.1(11.2)$ & $6.8(2.4$ to 11.2$)$ & 0.003 \\
\hline Social & $75.1(24.9)$ & $96.5(8.9)$ & 21.4 (15.1 to 27.6$)$ & $<0.001$ \\
\hline \multicolumn{5}{|l|}{ Symptoms } \\
\hline Fatigue & $31.3(21.0)$ & $14.4(11.9)$ & $-16.9(-22.6$ to -11.2$)$ & $<0.001$ \\
\hline
\end{tabular}




\begin{tabular}{l|c|c|c|c} 
Nausea/Vomiting & $6.8(14.2)$ & $1.2(5.9)$ & $-5.6(-9.3$ to -2.0$)$ & 0.002 \\
\hline Pain & $18.5(23.0)$ & $11.0(18.9)$ & $-7.5(-14.5$ to -0.5$)$ & 0.035 \\
Dyspnoea & $21.6(25.3)$ & $4.7(13.0)$ & $-16.9(-23.6$ to -10.2$)$ & $<0.001$ \\
Insomnia & $26.8(30.7)$ & $21.1(24.7)$ & $-5.6(-14.9$ to 3.6$)$ & 0.230 \\
Appetite Loss & $12.7(22.1)$ & $2.3(10.3)$ & $-10.3(-16.1$ to -4.6$)$ & 0.001 \\
Constipation & $18.3(25.7)$ & $1.9(12.5)$ & $-16.4(-23.2$ to -9.7$)$ & $<0.001$ \\
Diarrhoea & $8.0(16.4)$ & $2.8(10.9)$ & $-5.2(-9.8$ to -0.5$)$ & 0.029 \\
Financial Difficulties & $26.8(30.7)$ & $21.1(24.7)$ & $-5.6(-14.9$ to 3.6$)$ & 0.230 \\
\hline
\end{tabular}

* Missing data for the following variables (number of cases missing): $\mathrm{VO}_{2 \max }(17)$, Handgrip strength (10), LEG strength (11), steps and MVPA (6). "ABS" denotes absolute; "REL" denotes relative; ${ }^{ \pm}$MVPA refers to minutes spent in moderate-to-vigorous intensity physical activity ( $\geq 3$ METS) per day. 
Table 3. Association of the combined group's demographics, physical measures and patientreported outcomes with steps/day and MVPA

\begin{tabular}{|c|c|c|c|c|c|c|}
\hline & \multicolumn{3}{|c|}{ MVPA } & \multicolumn{3}{|c|}{ Steps/Day } \\
\hline & $\beta$ & $95 \% \mathrm{Cl}$ & $p$ & $\beta$ & $95 \% \mathrm{Cl}$ & $p$ \\
\hline Age (y) & -0.4 & -1.9 to 1 & 0.553 & -41.8 & -101.8 to 18.2 & 0.171 \\
\hline $\mathrm{BMI}\left(\mathrm{kg} \cdot \mathrm{m}^{-2}\right)$ & -7.8 & -10.1 to -5.5 & $<0.001$ & -74.0 & -181 to 32.9 & 0.173 \\
\hline Body mass (kg) & -2.6 & -3.4 to -1.8 & $<0.001$ & -25.8 & -63.2 to 11.5 & 0.174 \\
\hline Fitness Measures & & & & & & \\
\hline $\begin{array}{l}\mathrm{VO}_{2 \max }\left(\mathrm{ml} \bullet \mathrm{kg}^{-}\right. \\
\left.{ }^{1} \bullet \min ^{-1}\right)\end{array}$ & 6.0 & 3.5 to 8.5 & $<0.001$ & 210.1 & 110.3 to 309.8 & $<0.001$ \\
\hline Fitness Percentile & 1.3 & 0.8 to 1.8 & $<0.001$ & 40.6 & 19 to 62.1 & $<0.001$ \\
\hline $\begin{array}{l}\text { HandGrip } \\
\text { Strength }_{\mathrm{ABS}}(\mathrm{kg})\end{array}$ & 1.9 & -0.4 to 4.3 & 0.108 & 63.2 & -29.5 to 155.9 & 0.180 \\
\hline HandGrip & & & & & & \\
\hline $\begin{array}{l}\text { Strength }{ }_{\text {REL }} \\
\left(\mathrm{kg} \bullet \mathrm{kg}^{-1}\right)\end{array}$ & 465.0 & 347.1 to 582.8 & $<0.001$ & 6945.4 & 1369.8 to 12520.9 & 0.015 \\
\hline $\begin{array}{l}\text { LEG Strength }{ }_{A B S} \\
(\mathrm{~kg})\end{array}$ & 0.3 & -0.3 to 0.9 & 0.320 & 27.1 & 4.9 to 49.2 & 0.017 \\
\hline $\begin{array}{l}\text { LEG Strength }{ }_{\text {REL }} \\
\left(\mathrm{kg} \bullet \mathrm{kg}^{-1}\right)\end{array}$ & 75.6 & 39.7 to 111.5 & $<0.001$ & 2207.8 & 761.7 to 3653.9 & 0.003 \\
\hline GLTEQ & 0.7 & 0.2 to 1.2 & 0.010 & 51.6 & 32.4 to 70.8 & $<0.001$ \\
\hline Life Space & 0.5 & -0.2 to 1.2 & 0.174 & 35.2 & 5.8 to 64.6 & 0.019 \\
\hline FACIT-Fatigue & 1.1 & -0.8 to 2.9 & 0.258 & 138.3 & 67.1 to 209.5 & $<0.001$ \\
\hline EORTC QLQ-C30 & & & & & & \\
\hline Function Scales & & & & & & \\
\hline Global & 0.6 & -0.2 to 1.3 & 0.152 & 32.3 & 0.9 to 63.7 & 0.044 \\
\hline Physical & 0.4 & -0.6 to 1.5 & 0.411 & 73.9 & 34.3 to 113.5 & $<0.001$ \\
\hline Role & 0.4 & -0.4 to 1.2 & 0.315 & 47.9 & 17.8 to 77.9 & 0.002 \\
\hline Emotional & 0.4 & -0.4 to 1.2 & 0.329 & 21.8 & -11.9 to 55.5 & 0.202 \\
\hline
\end{tabular}




\begin{tabular}{|c|c|c|c|c|c|c|}
\hline Cognitive & -0.7 & -1.7 to 0.4 & 0.199 & 6.1 & -36.2 to 48.3 & 0.777 \\
\hline Social & 0.3 & -0.6 to 1.1 & 0.504 & 43.9 & 10.9 to 76.9 & 0.010 \\
\hline \multicolumn{7}{|l|}{ Symptoms } \\
\hline Fatigue & -0.5 & -1.4 to 0.3 & 0.206 & -60.5 & -92.4 to -28.5 & $<0.001$ \\
\hline Nausea/Vomiting & -0.8 & -2.1 to 0.5 & 0.228 & -51.8 & -104.8 to 1.2 & 0.055 \\
\hline Pain & 0.0 & -0.6 to 0.7 & 0.953 & -13.7 & -40.7 to 13.3 & 0.319 \\
\hline Dyspnoea & -0.2 & -0.9 to 0.5 & 0.518 & -21.0 & -48.7 to 6.6 & 0.134 \\
\hline Insomnia & 0.1 & -0.4 to 0.6 & 0.737 & -13.9 & -33.9 to 6.1 & 0.171 \\
\hline Appetite Loss & 0.0 & -0.8 to 0.9 & 0.952 & -47.6 & -82 to -13.1 & 0.007 \\
\hline Constipation & 0.3 & -0.4 to 1 & 0.414 & -2.9 & -32.8 to 27 & 0.848 \\
\hline Diarrhoea & -0.4 & -1.3 to 0.6 & 0.470 & -38.4 & -77.8 to 1 & 0.056 \\
\hline Financial Difficulties & 0.1 & -0.4 to 0.6 & 0.737 & -13.9 & -33.9 to 6.1 & 0.171 \\
\hline
\end{tabular}

MVPA refers to moderate-to-vigorous intensity physical activity ( $\geq 3$ METS). "ABS" denotes absolute; "REL" denotes relative. 

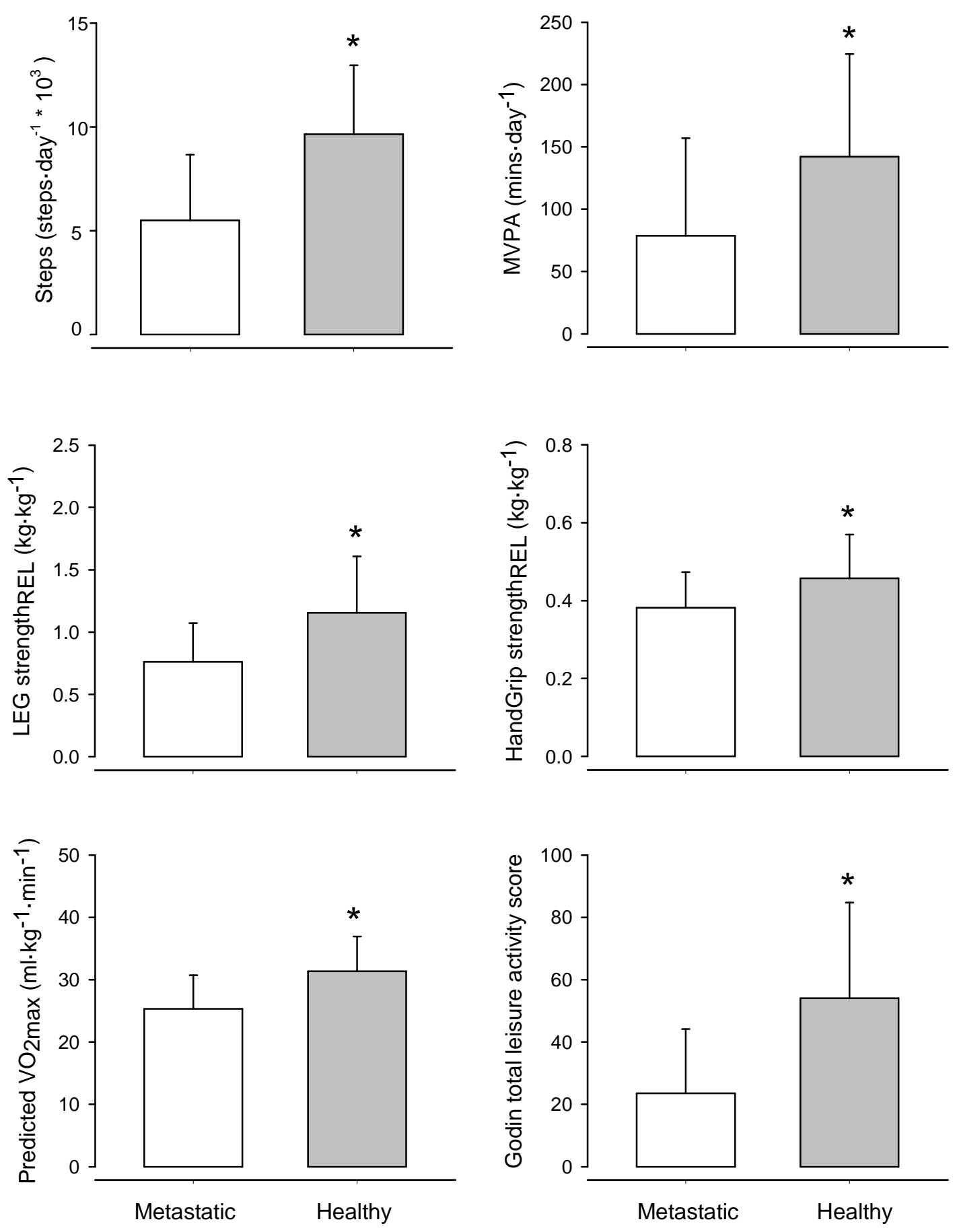

Comparison of the metastatic and healthy groups 